\title{
Study on the differential proteomics of rat hippocampal mitochondria during deep hypothermic circulatory arrest
}

\author{
Yongjun Gao $^{1 \#}$, Xiuli Han ${ }^{2 \#}$, Liang Wei $^{3}$, Yong Yuan ${ }^{1}$, Chengbin Zhao ${ }^{1}$, Ming Zhang ${ }^{1}$, Zheng Wang ${ }^{1}$, \\ Xuhui $\mathrm{Li}^{1}$, Wei $\mathrm{Xu}^{1}$ \\ ${ }^{1}$ Department of Neurosurgery, Second Affiliated Hospital of Kunming Medical University, Kunming, China; ${ }^{2}$ Department of Stomatology, \\ Children's Hospital Affiliated to Kunming Medical University, Kunming, China; ${ }^{3}$ Department of Neurosurgery, East Hospital, Tongji University \\ School of Medicine, Shanghai, China \\ Contributions: (I) Conception and design: Y Gao, X Han; (II) Administrative support: W Xu; (III) Provision of study materials or patients: Y Yuan; (IV) \\ Collection and assembly of data: L Wei, C Zhao; (V) Data analysis and interpretation: Y Gao, M Zhang, Z Wang, X Li; (VI) Manuscript writing: All \\ authors; (VII) Final approval of manuscript: All authors. \\ \#These authors contributed equally to the work as co-first authors. \\ Correspondence to: Wei Xu. Second Affiliated Hospital of Kunming Medical University, Wuhua District, Kunming 650101, China. \\ Email: WeiXuzxc@163.com.
}

Background: This study aimed to investigate the effect of deep hypothermic circulatory arrest (DHCA) on rat hippocampal mitochondrial protein expression and its differential proteomics, and explore the potential mechanisms behind the effect.

Methods: We used internal jugular vein reflux and tail artery perfusion methods to establish the rat cardiopulmonary bypass (CPB) model. Rats were dissected to obtain the hippocampus, and the hippocampal mitochondria were purified. The mitochondrial morphology and the mitochondrial marker cytochrome $\mathrm{C}$ oxidase (COX) qualitatively examined via transmission electron microscopy and western-blot analysis, respectively. The qualified samples were subjected to isobaric tags for relative and absolute quantification (iTRAQ); we then established the CPB model again to obtain the rat hippocampus for cryoultramicrotomy, and used immunofluorescent double staining technique to qualitatively and semi-quantitatively verify two representative differentially expressed proteins.

Results: By searching the Mascot 2.2 database, 29 differentially expressed proteins were obtained with statistical significance, including 21 known proteins and 8 unknowns. The expression level of COX and monoacylglycerol lipase did not change significantly $(\mathrm{P}>0.05)$ during the hyperacute phase; however, their intracellular localizations were altered.

Conclusions: DHCA induced the differential expression of 29 rat hippocampal mitochondrial proteins, some of which had altered intracellular localization. We speculated that the localized alteration of these proteins is one of the neuroprotection mechanisms that occurs during DHCA.

Keywords: Deep hypothermic circulatory arrest (DHCA); mitochondrion; differential proteomics; isobaric tags for relative and absolute quantification (iTRAQ); neuroprotection

Submitted Dec 10, 2020. Accepted for publication Feb 10, 2021.

doi: 10.21037/atm-21-95

View this article at: http://dx.doi.org/10.21037/atm-21-95

\section{Introduction}

Deep hypothermic circulatory arrest (DHCA), as a medical technique, has been applied in the surgical treatment of special diseases in cardiac surgery, neurosurgery, and others (1). Application of DHCA can protect neurocognitive function and reduce hypoxic-ischemic damage $(2,3)$; meanwhile, however, it also presents new medical complications (4). Nonetheless, protection can be achieved 
by ischemic preconditioning, which exerts cellular and mitochondrial protection via faster recovery of glial-specific S100 calcium binding protein $\mathrm{B}$, favorable regional antitoxic response and lower systemic lactate levels (5). Thus, it shows the importance of mitochondria in stabilizing neuronal functions after DHCA. In the cerebrum, the hippocampus is the most sensitive organ to hypoxicischemic damage, therefore the hippocampal mitochondria become one of the organelles to show a rapid response to cerebral hypoxic-ischemic damage. Thus, the hippocampus is the critical factor of determining the neuronal outcome after hypoxic-ischemic damage (6), including mitochondriamediated hippocampal neuron apoptosis and so on (7). The corresponding protein changes are inevitable throughout the whole process, and the study of differential proteomics is considered a very effective way to investigate the protein changes under different functional conditions (8).

This study utilized the combination of isobaric tags for relative and absolute quantitation (iTRAQ) and liquid chromatography-tandem mass spectrometry (LC-MS/MS) techniques to obtain the differentially expressed proteins of rat hippocampal mitochondria during DHCA, and reversely validated two representatives of the resulting differentially expressed proteins qualitatively and semi-quantitatively. Our study was composed of 4 parts: firstly, the establishment of the rat model for DHCA and validation of the model's effect; secondly, purification and validation of rat hippocampal mitochondria (by morphological examination and western blot determination for marker proteins); thirdly, mass spectrometric analysis, combining iTRAQ and LC-MS/MS, to study the differential proteomics of the mitochondrial samples; fourthly, reverse validation of two representatives, COX protein and monoacylglycerol lipase of the resulting differentially expressed proteins qualitatively and semi-quantitatively by immunofluorescence double staining and western blot. Finally, we elaborated the possible neuroprotection mechanism of DHCA against hypoxic-ischemic damage.

We present the following article in accordance with the ARRIVE reporting checklist (available at http://dx.doi. org/10.21037/atm-21-95).

\section{Methods}

\section{Materials}

The materials used included 40 Sprague-Dawley (SD) rats (Laboratory Animal Center of Kunming Medical University,
China); membrane oxygenator (MicroPort, Dongguan, China); peristaltic pump (VCL Pump, Changzhou, China); small animal ventilator (Upwards Teksystems, USA); Microm microtome (Thermo Fisher Scientific, Waltham, MA, USA); rabbit anti-mouse HIF- $1 \alpha$ monoclonal antibody (Beijing Biosynthesis Biotechnology, Beijing, China); Optical Microscope Imaging Device (JVC, Yokohama, Japan); Cell Medical Image Analysis System (THME, Chongqing, China); Transmission Electron Microscope (JEOL, Tokyo, Japan); Mitochondria Isolation Kit (Thermo Fisher Scientific, Waltham, MA, USA); Q-Exactive Mass Spectrometer (Thermo Fisher Scientific, Waltham, MA, USA); AKTA Purifier 100 (GE healthcare, Chicago, IL, USA); Centrifuge 5430R (Eppendorf, Hamburg, Germany), Concentrator plus (Eppendorf, Hamburg, Germany); 600V Electrophoresis Power Supply EPS601 (GE healthcare, Chicago, IL, USA); WFZ UV-2100 Ultraviolet Visible Spectrophotometer (Unico, Franksville, WI, USA); LSM 510 Meta Laser Scanning Confocal Microscope (ZEISS, Oberkochen, Germany); Chemiluminescence Imaging System (Bio-rad, Hercules, CA, USA); Electrophoresis Apparatus and Wet-transfer System (Bio-rad, Hercules, CA, USA), Leica R Microtome (Leica, Wetzlar, Germany). AntiCOX 7a2/3, anti-mitochondria, and anti-monoglyceride lipase primary antibodies were all purchased from Santa Cruz Biotechnology (Santa Cruz, Dallas, TX, USA).

\section{Animal grouping and cardiopulmonary bypass (CPB) model establishment}

All the methods used in this study were done in accordance with the guidelines of Ethics Committees of Kunming Medical University for use and care of animals. All the experimental protocols were approved by the Ethics Committees of Kunming Medical University.

The 40 Sprague-Dawley (SD) rats were randomly divided into 4 groups: Normal circulation group (NC group, blank control, $36.5-37.5^{\circ} \mathrm{C}, \mathrm{n}=12$ ); normothermic circulatory arrest group (NTCA group, $36.5-37.5^{\circ} \mathrm{C}$, $\mathrm{n}=12)$; DHCA group $\left(<20^{\circ} \mathrm{C}, \mathrm{n}=12\right)$, and the remaining 4 rats were used to provide blood to prefilled pipes for CPB. The rats were placed in a supine position under tracheal intubation anesthesia to expose right internal jugular vein and tail artery, which were then cannulated with a 16-gauge catheter with lateral eyes and 22-gauge intravenous indwelling needle, respectively. Blood was drained from the right internal jugular vein and sequentially through the $\mathrm{CPB}$ circuit composed of a variable temperature reservoir, 
a peristaltic pump, a membrane oxygenator, then reentered rat via its tail artery. During the $\mathrm{CPB}$, the oxygen flow and the temperature of the reservoir were adjusted based on blood gas and the core body temperature. When the target temperature (rectal) of each group was reached, the circulation was arrested for 10 minutes, and a rapid craniotomy was conducted to obtain the rat hippocampus and frontal cortex that were then fixed in liquid nitrogen and $4 \%$ paraformaldehyde, respectively.

\section{Hematoxylin-eosin and immunobistochemical staining}

After 6 hours fixation in $4 \%$ paraformaldehyde, the frontal cortex was placed in $30 \%$ sucrose at $4{ }^{\circ} \mathrm{C}$ overnight, then fixed in $4 \%$ paraformaldehyde for more than 24 hours. Afterwards, the sample was washed 3 times in phosphate buffered saline (PBS) (10 minutes each time), dehydrated by alcohol gradient, rinsed with distilled water for 3 minutes, cleared by xylene twice ( 7.5 minutes each time), and then embedded in paraffin for 3-4 hours. The resulting block was continuously cut into 5,10 , and $20 \mu \mathrm{m}$ sections, which were then subjected to conventional hematoxylin-eosin (HE) and immunohistochemical (IHC) staining using avidin biotin complex (ABC) method.

\section{Mitochondria purification}

The rat hippocampus samples were thawed naturally, washed with PBS, cut into small pieces, and then homogenized in $800 \mu \mathrm{L}$ PBS on ice. Centrifugation was then performed at $1,000 \times \mathrm{g}$ for 3 minutes at $4{ }^{\circ} \mathrm{C}$. The pellet was resuspended by $800 \mu \mathrm{L}$ bovine serum albumin (BSA)/Reagent A. Any solution on the inner tube wall was spun down by medium-speed centrifugation for 5 seconds. Afterwards, the sample was incubated on ice for 2 minutes followed by the addition of $10 \mu \mathrm{L}$ Reagent $\mathrm{B}$, mediumspeed centrifugation for 5 seconds, and incubation on ice for 5 minutes. After maximum-speed centrifugation, $800 \mu \mathrm{L}$ of Reagent $\mathrm{C}$ was mixed with the sample, which was then subjected to $700 \times \mathrm{g}$ centrifugation for 10 minutes, and the resulting supernatant was subjected to $3,000 \times \mathrm{g}$ centrifugation for 5 minutes at $4{ }^{\circ} \mathrm{C}$. The resulting pellet was washed with $500 \mu \mathrm{L}$ Reagent $\mathrm{C}$, followed by $12,000 \times \mathrm{g}$ centrifugation for 5 minutes. About $0.1 \mathrm{~g}$ mitochondriacontaining pellet was transferred to a new tube, and fixed using $1 \mathrm{~mL} 2 \%$ paraformaldehyde/2.5\% glutaraldehyde solution for $2-4$ hours at $4{ }^{\circ} \mathrm{C}$. The preparation was then sent for electron microscopy examination.

\section{Ultrastructural examination of purified mitochondria}

The purified and fixed mitochondria sample was washed with $0.1 \mathrm{~mol} / \mathrm{L}$ natrium cacodylicum at $4{ }^{\circ} \mathrm{C}$ for at least 4 hours, the wash buffer was changed 5 times, and then fixed in $1 \%$ osmic acid $/ 0.1 \mathrm{~mol} / \mathrm{L}$ natrium cacodylicum buffer. Afterwards, the sample was dehydrated with alcohol gradient $(50 \%, 70 \%, 80 \%, 90 \%$, and $100 \%, 10$ minutes each) followed by exchanging with desiccated trimethylene oxides gradient 3 times (10 minutes each time). The sample was immersed in trimethylene oxides/embedding medium (1:1) for 1 hour, in trimethylene oxides/embedding medium (1:3) for 3 hours, and in embedding medium for 1 hour. The sample was then embedded in freshly prepared EPON812 epoxy resin embedding medium, and encapsuled and labeled with numbers. After the resin was polymerized and trimmed, the sample was sectioned to slices of $1 \mu \mathrm{m}$ thickness. The $1 \mu \mathrm{m}$ slices were further sectioned into $50 \mathrm{~nm}$ ultra-thin slices. The slices were then double stained with uranyl acetate and lead citrate before being examined and imaged using a JEM-100CX transmission electron microscope.

Proteins of a $30 \mu \mathrm{g}$ sample of purified mitochondria were separated by sodium dodecyl sulfate polyacrylamide gel electrophoresis (SDS-PAGE) and transferred to $0.45 \mu \mathrm{m}$ polyvinylidene difluoride (PVDF) membrane. The membrane was immersed in $5 \%$ non-fat milk [in trisbuffered saline and Tween 20 (TBST), pH 7.5] and incubated at room temperature with gentle orbital shaking for 1 hour. Then, the membrane was incubated with primary antibody (1:1,000 in blocking reagent II) at room temperature for 30 minutes and then $4{ }^{\circ} \mathrm{C}$ overnight. The membrane was washed 7 times, 5 minutes each time, and then incubated with secondary antibody for 40 minutes. Following that, the membrane was washed 7 times, 5 minutes each time, and then subjected to chemiluminescent detection.

\section{Image analysis of the mitochondrial ultrastructure}

Electron microscopy images of the mitochondrial ultrastructure were analyzed two-dimensionally and threedimensionally using image analysis software (National Institutes of Health, Bethesda, MD, USA).

\section{Sample preparation and SDS-PAGE}

The purified mitochondria samples were examined by 
Bradford assay (Thermo Fisher Scientific, Waltham, MA, USA), and the protein concentration of the NC group was $1.68 \mu \mathrm{g} / \mu \mathrm{L}$, the NTCA group was $3.95 \mu \mathrm{g} / \mu \mathrm{L}$, and that of the DHCA group was $3.73 \mu \mathrm{g} / \mu \mathrm{L}$. The SDT buffer was mixed with $150 \mu \mathrm{g}$ of each sample individually, then boiled for 5 minutes, ultrasonicated for 20 minutes, boiled for 5 minutes, and then subjected to $14,000 \times \mathrm{g}$ centrifugation for 25 minutes. About $5 \mu \mathrm{L}$ of the resulting supernatant was mixed with $5 \times$ SDS sample buffer, and then boiled for 5 minutes before 14,000 $\times g$ centrifugation for 20 minutes. The resulting supernatant was used for $12.5 \%$ SDS-PAGE analysis. Then, the gel was stained with Coomassie brilliant blue.

\section{Enzymolysis and peptide quantification}

About $150 \mu \mathrm{g}$ protein sample was mixed with $200 \mu \mathrm{L}$ uric acid (UA) buffer $(8 \mathrm{~mol} / \mathrm{L}$ Urea, $150 \mathrm{mmol} / \mathrm{L}$ Tris-HCl $\mathrm{pH} 8.0$ ), and then subjected to $14,000 \times \mathrm{g}$ centrifugation for 15 minutes. Another $200 \mu \mathrm{L}$ UA buffer was added to the filter and centrifugated at 14,000 $\times \mathrm{g}$ for 15 minutes. After discarding the filtrate, $100 \mu \mathrm{L}$ indole-3-acetic acid (IAA) $(50 \mathrm{mmol} / \mathrm{L}$ IAA in UA) was added, and vortexed at $600 \mathrm{r} / \mathrm{mn}$ for 1 minute before incubation at room temperature in the dark for 30 minutes. Afterwards, the protein sample was subjected to centrifugation at $14,000 \times \mathrm{g}$ for 10 minutes, followed by 2 rounds of $100 \mu \mathrm{L}$ UA buffer addition and 10-minutes centrifugation at $14,000 \times \mathrm{g}$, and then 2 rounds of $100 \mu \mathrm{L}$ dissolution buffer addition and 10 -minute centrifugation at $14,000 \times \mathrm{g}$. Subsequently, $40 \mu \mathrm{L}$ trypsin buffer $(2 \mu \mathrm{g}$ trypsin in $40 \mu \mathrm{L}$ dissolution buffer) was added to the sample, vortexed at $600 \mathrm{r} / \mathrm{mn}$ for 1 minute, and incubated at $37{ }^{\circ} \mathrm{C}$ for $16-18$ hours. Afterwards, a new collection tube was used to collect the filtrate after 10-minutes of centrifugation at 14,000 $\times \mathrm{g}$. The obtained peptides in the collected filtrate were quantified using a spectrophotometer at optical density (OD) (9).

\section{Peptide labeling}

According to iTRAQ Reagent-8plex Multiplex Kit (AB SCIEX, Framingham, MA, USA) handbook, $18 \mu \mathrm{g}$ of sample from each group was labeled. The iTRAQ tags 113 to 118 were used to label NC- 1, NTCA-1, DHCA-1, NC-2, NTCA-2, and DHCA-2, respectively.

\section{Capillary high performance liquid chromatography}

Each sample was separated using nano-flow HPLC system
Easy nLC (Thermo Fisher Scientific, Waltham, MA, USA). Buffer A was $0.1 \%$ formic acid aqueous solution and Buffer B was $0.1 \%$ formic acid acetonitrile aqueous solution $(84 \%$ acetonitrile). The HPLC column was balanced with $95 \%$ Buffer A. The sample was loaded onto sample loading column $(2 \mathrm{~cm} \times 100 \mu \mathrm{m} 5 \mu \mathrm{m}-\mathrm{C} 18)$ via autosampler, then separated via analytical column $(75 \mu \mathrm{m} \times 100 \mathrm{~mm}$ $3 \mu \mathrm{m}-\mathrm{C} 18)$, and the flow rate was set as $250 \mathrm{~nL} / \mathrm{min}$. The corresponding liquid phase gradient was as follows: 0-100 min, Buffer B linear gradient was from $0-35 \%$; $100-108$ min, Buffer B linear gradient was from $35-100 \%$; 108-120 min, Buffer B was maintained at $100 \%$.

\section{Mass spectrometry and Mascot search}

Each sample was separated via capillary high performance liquid chromatography before being subjected to mass spectrometry analysis by Q-Exactive Mass Spectrometer (Thermo Fisher). The resulting mass spectrometry data were then subjected to database search. The filter parameters were as follows: Protein false discovery rate $($ FDR $\leq 0.01$, Peptide FDR $\leq 0.01$ (10).

\section{Quantitative analysis}

The software ProteomicsTools 3.1.6 (The Moritz Lab, Seattle, WA, http://tools.proteomecenter.org/software. php) was used to extract peptide ion peak intensity values, and normalize the signal intensity to the median value of each tag. The peptide quantification result was the ratio of the signal intensity of the tag with reference sample to the signal intensity of other tags. The protein quantification result was the median of the quantification result of the qualified peptides. The final quantification result was normalized by the ratio median of each tag to eliminate the sample loading error. The quantification ratios were all referred to the NC group, for example, NTCA-1 group/ NC-1 group, i.e., 114/113, and finally the differentially expressed proteins were obtained.

\section{Immunofluorescence double staining}

The CPB model was established again to obtain the hippocampal sample for cryoultramicrotomy. The hippocampal sample was sectioned to $8-12 \mu \mathrm{m}$ thickness slices and fixed in $95 \%$ acetone for 30 minutes, air-dried at room temperature for 15 minutes, rinsed 3 times with PBS for 5 minutes each time, then immersed in $0.3 \%$ 
A

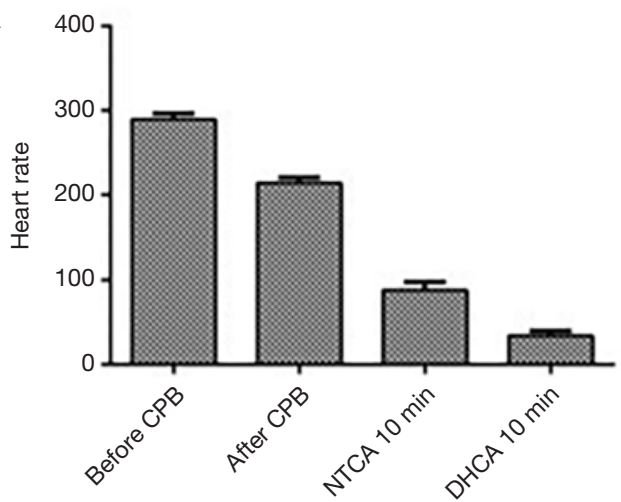

B

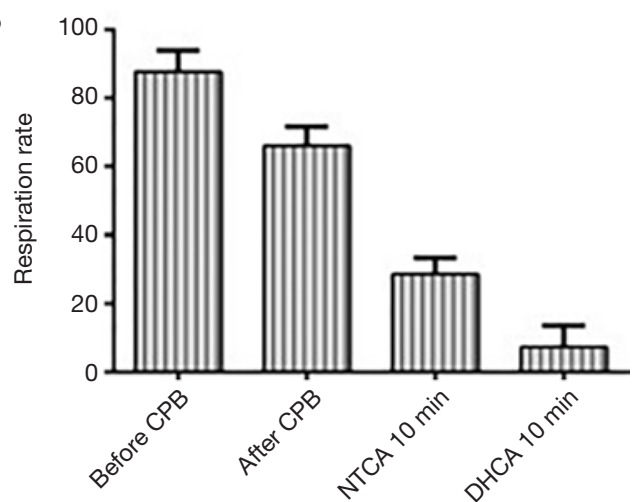

Figure 1 Comparison of heart and respiration rates of the experimental rats at different stages $(\bar{x} \pm s)$. Heart rate $(\mathrm{A})$ and respiration rate $(\mathrm{B})$ of each group of rats were recorded before and after CPB, 10 minutes post-NTCA, 10 minutes post-DHCA. CPB, cardiopulmonary bypass; NTCA, normothermic circulatory arrest group; DHCA, deep hypothermic circulatory arrest. Comparison of heart and respiration rates of the before $\mathrm{CPB}$ group with the after $\mathrm{CPB}$ : $\mathrm{P}<0.05$; comparison of heart and respiration rates of the 10 minutes post-NTCA group with the after $\mathrm{CPB}$ : $\mathrm{P}<0.05$; comparison of heart and respiration rates of the 10 minutes post-DHCA group with the 10 minutes post-NTCA: $\mathrm{P}<0.05$.

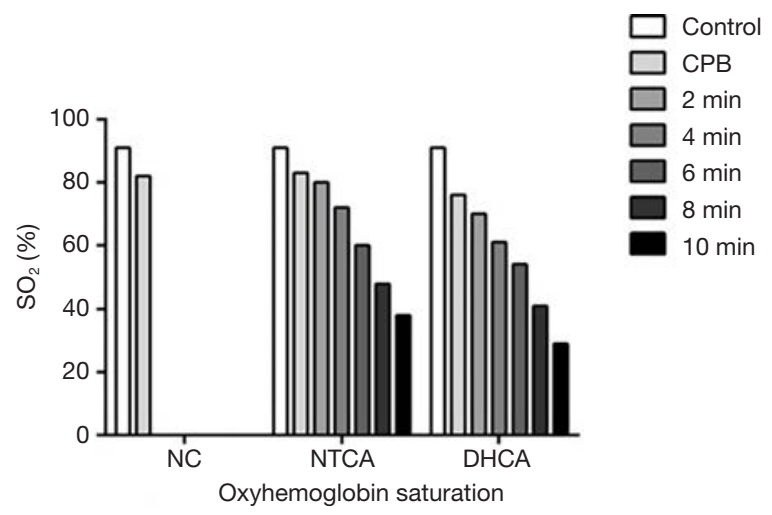

Figure 2 The oxyhemoglobin saturation levels of the NC, NTCA, and DHCA groups were measured at the indicated time points and plotted. NC, normal control; NTCA, normothermic circulatory arrest group; DHCA, deep hypothermic circulatory arrest. Comparison of the oxyhemoglobin saturation level of the $\mathrm{NC}$ group with the other two groups at $10 \mathrm{~min}: \mathrm{P}<0.05$.

tritone $\mathrm{X}-100$ for 30 minutes, rinsed 3 times with PBS for 5 minutes each time, and then blocked using normal goat serum for 45 minutes. The serum was discarded and the slices were incubated with anti-COX $7 \mathrm{a} 2 / 3$ antibody (1:50-1:500) at $4{ }^{\circ} \mathrm{C}$ overnight. The slices were rinsed with PBS before incubation with secondary antibody [fluorescein isothiocyanate (FITC), 1:200] at room temperature in the dark for 1 hour. The slices were then rinsed 3 times with PBS for 5 minutes each time before 4',6-diamidino-2- phenylindole (DAPI) staining. The slices were then rinsed twice with PBS for 5 minutes each time before being examined under the fluorescent microscope. The western blot procedure was performed in the same way as described above.

\section{Statistical analysis}

Experiments were repeated three times, and the results were displayed as mean \pm standard deviation (SD). Statistical significance was defined as $\mathrm{P}<0.05$.

\section{Results}

\section{CPB model establishment}

The animal CPB model was successfully established and stably repeated. The difference of vital signs including heart rate, respiration rate, and oxyhemoglobin saturation, before and after the operation, are shown in Figures 1 and 2. The difference of the heart (Figure 1A) and respiration (Figure 1B) rates of each group before and after 10 minutes of $\mathrm{CPB}$ was significant $(\mathrm{P}<0.05)$. The difference in heart (Figure $1 A)$ and respiration (Figure $1 B$ ) rates of the NTCA group between post-10 minute of circulatory arrest and post-10 minute of $\mathrm{CPB}$ was significant $(\mathrm{P}<0.05)$. The difference in heart (Figure $1 A$ ) and respiration (Figure $1 B$ ) rates post-10 minute of circulatory arrest between the DHCA and NTCA groups was also significant $(\mathrm{P}<0.05)$. 


\section{HE and IHC staining}

The HE staining of the frontal cortex of each group showed no obvious structural change (Figure $3 A, B, C$ ). The IHC staining results showed that Nestin and HIF- $1 \alpha$ positive particles were evenly distributed in the cytoplasm of nerve cells, a few positive stains were also found in the nuclei and synapses, and the outlines of the nerve cells with positive staining of these two proteins were clearly observed (Figure 3D,E, F, G,H,I). A small amount of expression of Nestin and HIF-1 $\alpha$ were found in NC group, while that in NTCA group increased, and that in DHCA group showed significant increment $(\mathrm{P}<0.05$, Figure 3D,E,F,G,H,I, 7).

\section{Mitochondrial ultrastructure analysis}

As shown in Figure 4, transmission electron microscope at 5,000x and 10,000x magnification showed that the majority of the visualized structure was mitochondria, and a small amount of cell debris structure was also visible. Non-mitochondria organelles such as Golgi, endoplasmic reticulum (ER), and others were not observable. Transmission electron microscope at $30,000 \times$ showed the mitochondria double membrane structures were relatively intact, and the mitochondrial cristae and matrix were clearly observable. Compared to the NC group, mitochondria isolated from the DHCA group showed mild swelling, a small amount of the mitochondrial cristae fractured, while the membrane structure remained intact. The most obvious mitochondrial swelling phenomenon was observed in the NTCA group.

As shown in Figure 4, we found the mitochondrial membrane structure of the hippocampal CA1 region's pyramidal cells in the NTCA group were partially destroyed, disintegrated, or autolysed. With the extension of DHCA duration, the hippocampal neuronal mitochondria with better ultrastructural integrity were found in the DHCA group, and the damage of mitochondria internal structure was relatively modest in this group. We also found that in the DHCA group, the majority of the mitochondrial swelling was cristae type of swelling. Mitochondrial swelling in the NTCA group was caused by energy-impaired mitochondrial membrane damage due to mitochondrial acute osmotic swelling, and this change was more obvious than that in the NC group.

Pairwise comparison of mitochondrial perimeters in the NC, DHCA, and NTCA groups revealed a significant difference among groups $(\mathrm{F}=144.67, \mathrm{P}<0.05)$, and NTCA > DHCA > NC (Figure 5). Pairwise comparison of mitochondrial diameters in NC, DHCA, and NTCA groups revealed a significant difference among groups $(\mathrm{F}=129.54, \mathrm{P}<0.05)$, and NTCA $>$ DHCA $>$ NC (Figure 5). Comparison of mitochondrial average grey scale value in the DHCA or NTCA group to that in the NC group showed a significant difference $(\mathrm{F}=13.28, \mathrm{P}<0.05)$, whereas comparison between the DHCA and NTCA group showed no significant difference $(\mathrm{P}>0.05)$. Pairwise comparison of mitochondrial deformation parameter in the NC, DHCA, and NTCA groups revealed no significant difference among groups $(\mathrm{F}=2.35, \mathrm{P}>0.05)$.

Pairwise comparison of mitochondrial volume density $(\mathrm{Vv})$ showed a significant difference among groups $(\mathrm{F}=41.307, \mathrm{P}<0.05)$, and $\mathrm{NC}>\mathrm{DHCA}>\mathrm{NTCA}$ (Figure $6 A$ ). Pairwise comparison of mitochondrial numerical density $(\mathrm{Nv})$ revealed a significant difference among groups $(\mathrm{F}=105187.6, \mathrm{P}<0.05)$, and $\mathrm{NC}>\mathrm{DHCA}>\mathrm{NTCA}$ (Figure 6A). Pairwise comparison of mitochondrial mean Volume $(\mathrm{V})$ showed a significant difference among groups $(\mathrm{F}=12543.02, \mathrm{P}<0.05)$, and $\mathrm{NC}<\mathrm{DHCA}<\mathrm{NTCA}$ (Figure 6A). Pairwise comparison of mitochondrial $\sigma$ revealed a significant difference among groups $(\mathrm{F}=459.472$, $\mathrm{P}<0.05$ ), and NC $>$ DHCA $>$ NTCA (Figure 6B).

\section{Protein identification and significant differentially expressed proteins analysis}

Through LC-MS/MS analysis and Mascot 2.2 database searching, we obtained 5,440 unique peptides, 1,514 proteomes, 987 proteomes with more than two unique peptides, and 372 proteins with quantitative information. We chose the proteins with more than 1.5 fold quantitative differences in two repeated experiments. We calculated the $\log 2$ value of the ratio average of every repetitively labeled protein, and the corresponding $\mathrm{P}$ value. We defined the proteins with $\mathrm{P}$ value $<0.05$ as the significant differentially expressed proteins. Based on the above-mentioned 2 criteria, we obtained 29 differentially expressed proteins, of which 21 proteins = were known, and 8 were unknown proteins (Table 1).

The $\log 2$ value distribution of the ratio of each tag to the reference tag was shown as the quantitative ratio histogram distribution. Using the NTCA-1 group as an example (Figure 7), the $y$-axis was the protein number, and the $x$-axis was the $\log 2$ value of the ratio of NTCA- 1 group to $\mathrm{NC}-1$ group.

The Pearson correlation analysis of the ratio of NTCA-1 group and DHCA-1 group is shown in Figure 8, and the 

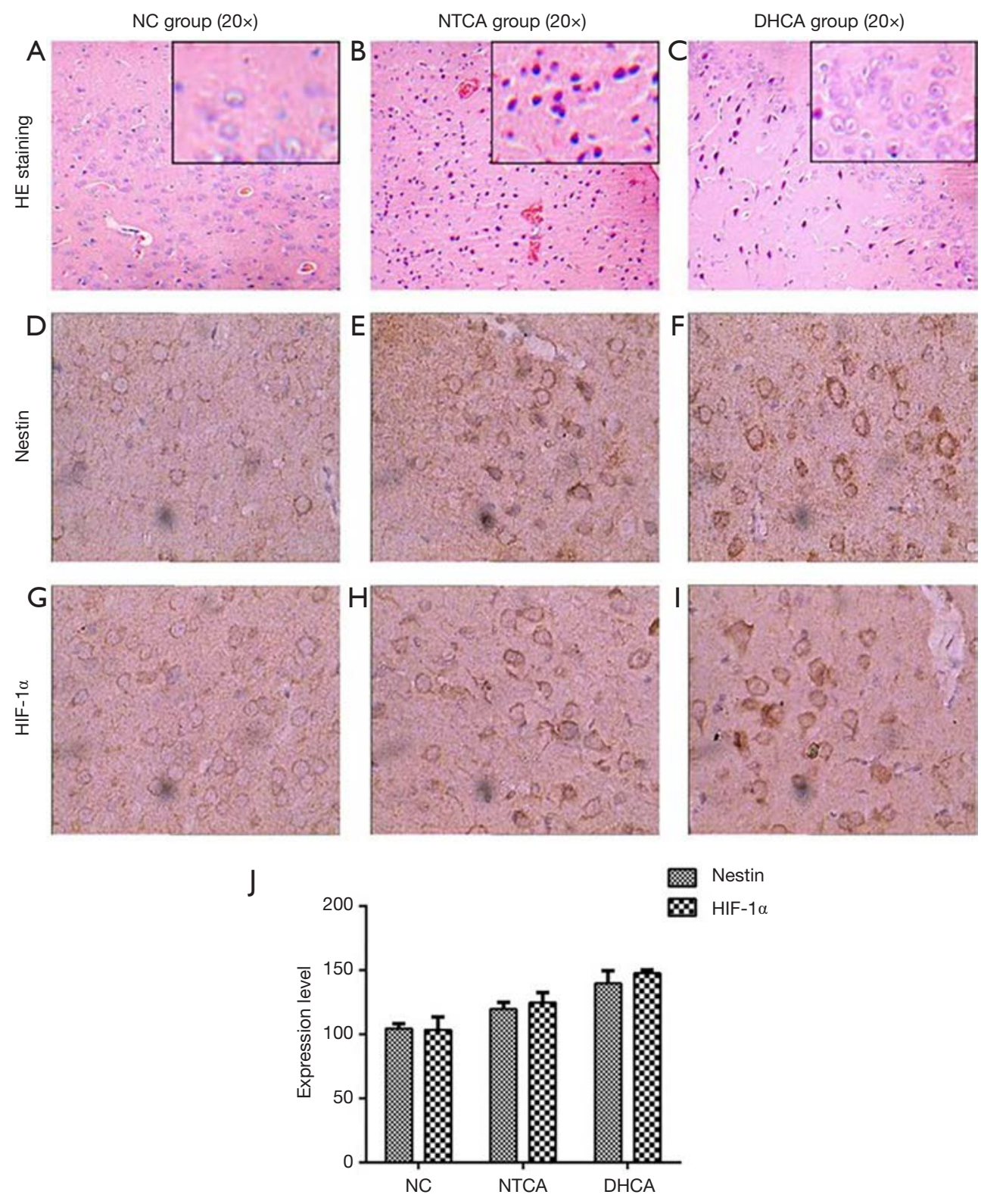

Figure $3 \mathrm{HE}$ and IHC staining of rat frontal cortex samples. (A,B,C) HE staining of the rat frontal cortex sections of indicated groups. (D,E,F) IHC staining for Nestin of the rat frontal cortex sections of indicated groups. (G,H,I) IHC staining for HIF-1 $\alpha$ of the rat frontal cortex sections of indicated groups. (J) Comparison of the average grey scale value of IHC staining for Nestin and HIF-1 $\alpha$ in the rat frontal cortex sections of indicated groups $(\bar{x} \pm s)$. Comparison of the average grey scale value of Nestin and HIF- $1 \alpha$ of NC group to that of the other two groups: $\mathrm{P}<0.05, \mathrm{~F}=26.356$. Comparison of the average grey scale value of Nestin and HIF- $1 \alpha$ of the DHCA group to that of the NTCA group: $\mathrm{P}<0.05, \mathrm{~F}=25.436$. HE, hematoxylin-eosin; IHC, immunohistochemical; DHCA, deep hypothermic circulatory arrest; NTCA, normothermic circulatory arrest group. 
$\mathrm{NC}$
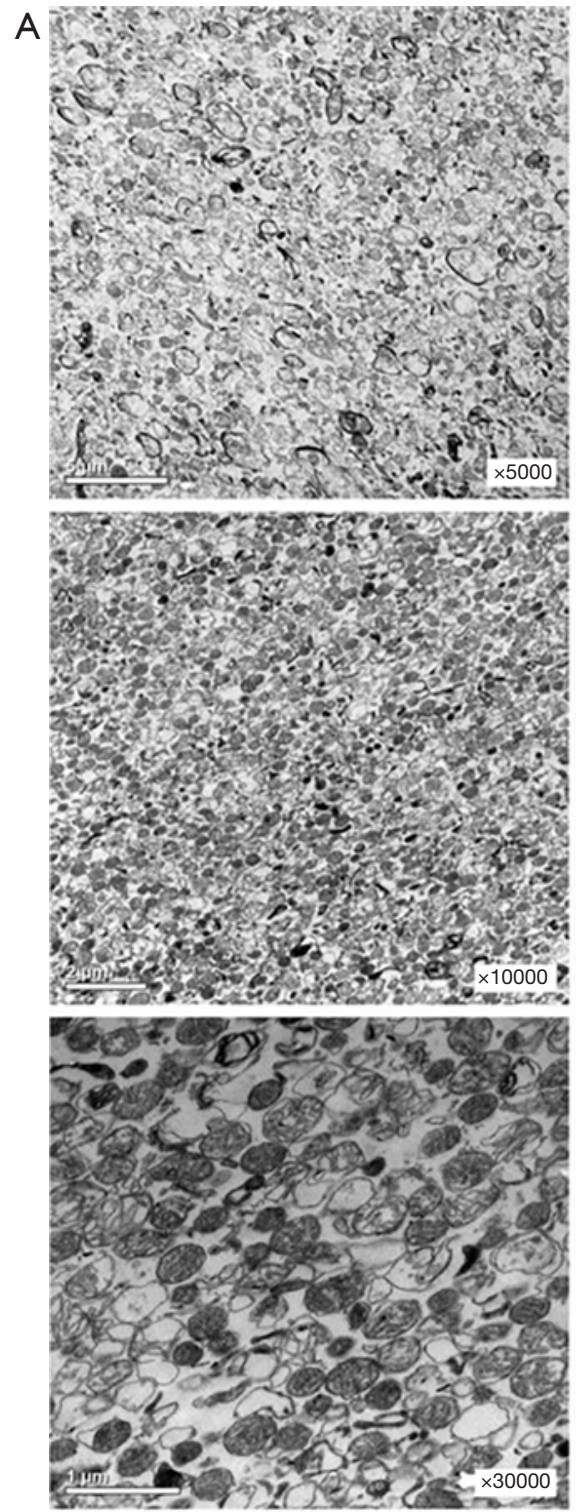

NTCA
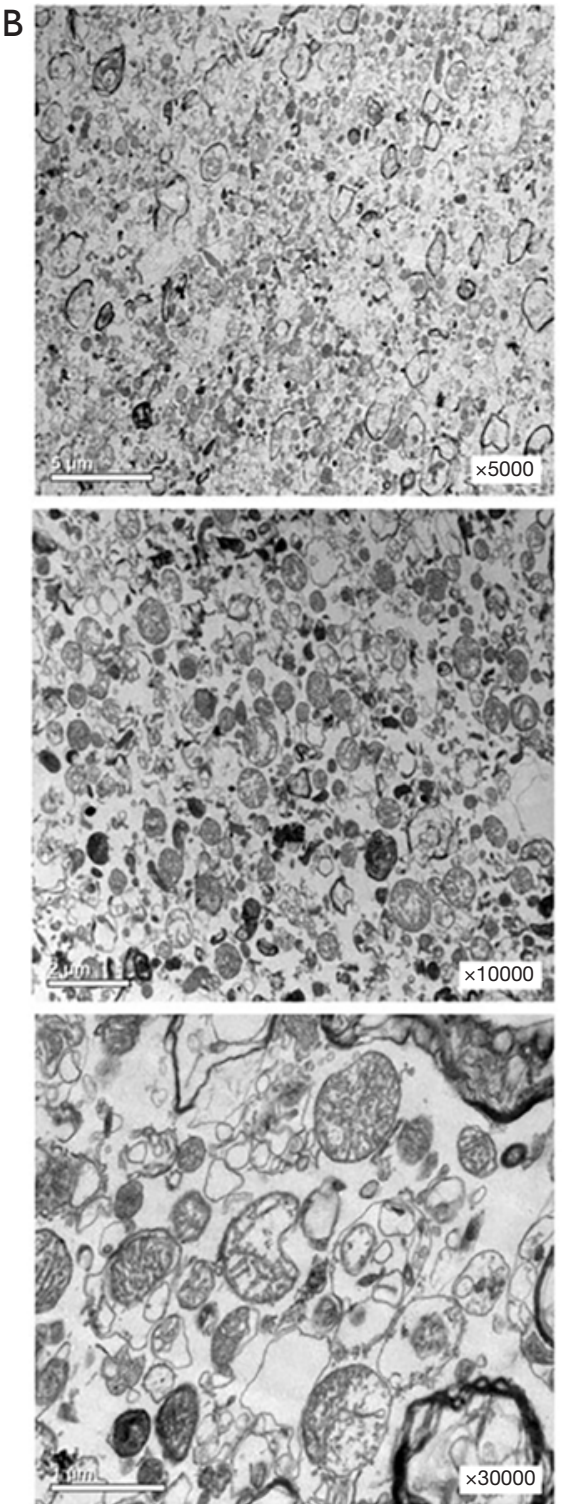

DHCA
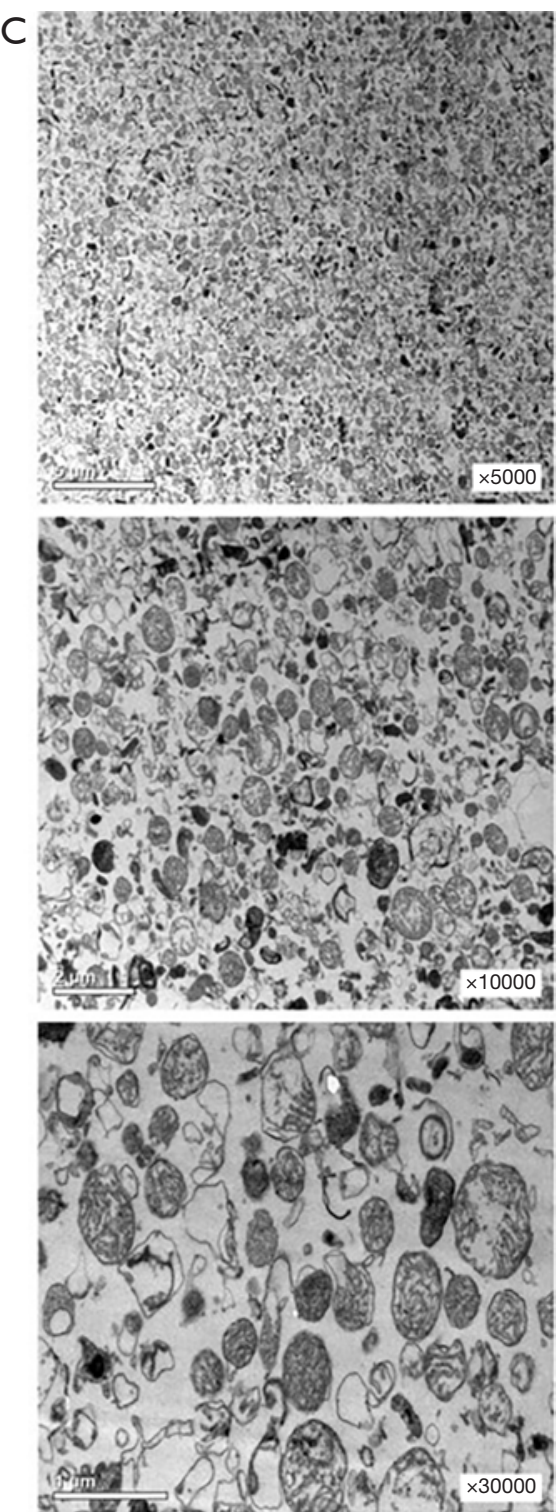

Figure 4 Transmission electron microscope images of rat hippocampal mitochondria. (A) Hippocampal mitochondria of rats in NC group. (B) Hippocampal mitochondria of rats in NTCA group. (C) Hippocampal mitochondria of rats in DHCA group . Representative images at $5,000 \times, 10,000 \times$, and 30,000× magnifications are shown. NC, normal control; NTCA, normothermic circulatory arrest group; DHCA, deep hypothermic circulatory arrest.

$x$-axis and $y$-axis were the iTRAQ ratio of NTCA-1 group and DHCA-1 group, respectively.

\section{Immunofluorescent staining and western blot analysis for cytochrome C oxidase (COX-IV)}

As shown in Figure $9 A, B, C$, the $\mathrm{COX}$ protein in the hippocampal neurons of the NTCA group was located in the cytoplasm, and outside of the nuclei of the hippocampal neurons. The merged image showed the neuron's intact outlines.

In the DHCA group, as shown in Figure 9D,E,F, the COX protein in the hippocampal neurons was located in the cytoplasm, and outside of the nuclei of the hippocampal 


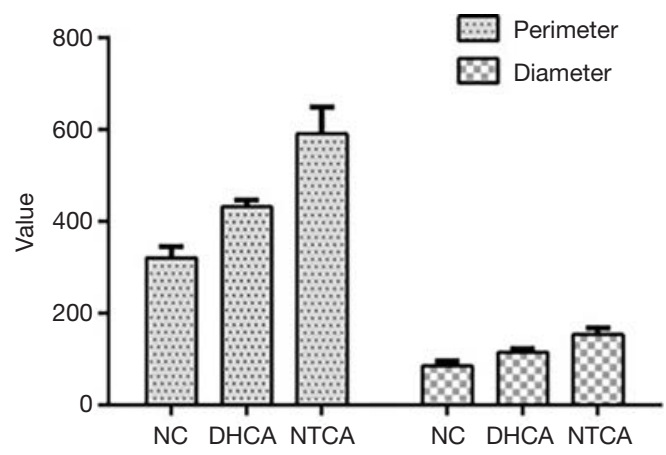

Figure 5 Mitochondrial two-dimensional parameters analysis of NC, DHCA, and NTCA groups. Mitochondrial perimeter and diameter were measured based on the transmission electron microscope images of rat hippocampal mitochondria in NC, NTCA, and DHCA groups. NC, normal control; NTCA, normothermic circulatory arrest group; DHCA, deep hypothermic circulatory arrest. Comparison of the mitochondrial perimeter and diameter of $\mathrm{NC}$ group to that of the other two groups: $\mathrm{P}<0.05$; Comparison of the perimeter and diameter of the DHCA group to that of the NTCA group: $\mathrm{P}<0.05$.
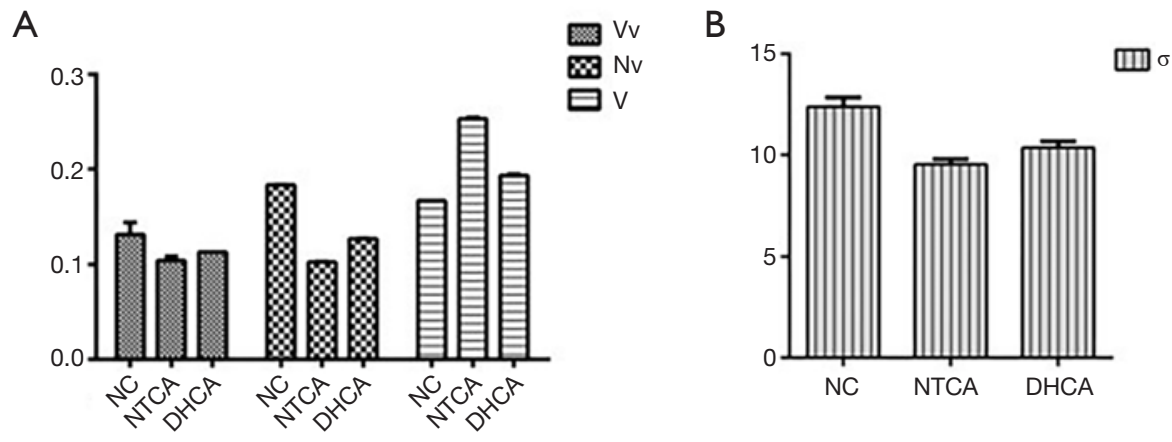

Figure 6 Comparison of mitochondrial $\mathrm{Vv}, \mathrm{Nv}, \mathrm{V}$ and $\sigma$ among NC, DHCA, and NTCA groups $(\mathrm{P}<0.05)$. (A) mitochondrial $\mathrm{V}_{\mathrm{v}}, \mathrm{Nv}, \mathrm{V}$ among NC, DHCA, and NTCA groups; (B) mitochondrial $\sigma$ among NC, DHCA, and NTCA groups. Vv, volume density; Nv, numerical density; V, volume; $\sigma$, mitochondrial membrane potential; NC, normal control; NTCA, normothermic circulatory arrest group; DHCA, deep hypothermic circulatory arrest. Comparison of the mitochondrial $\mathrm{Vv}, \mathrm{Nv}, \mathrm{V}$ and $\sigma$ of $\mathrm{NC}$ group to that of the other two groups: $\mathrm{P}<0.05$; Comparison of the $\mathrm{Vv}, \mathrm{Nv}, \mathrm{V}$ and $\sigma$ of the DHCA group to that of the NTCA group: $\mathrm{P}<0.05$.

neurons; however, slight overlap of the blue and red fluorescence might have existed at the contact site between the nuclei and the cytoplasm. The merged image showed the neuron's outlines. This suggested that COX protein moved from the cytoplasm towards the nuclei with the process of DHCA.

The western blot result clearly showed that the COX protein was around $17 \mathrm{kDa}$ (Figure 10). The grey scale value, ratio to internal control, and average value of each group are shown in Table 2. The grey scale ratio differences among the groups were not statistically meaningful $(\mathrm{P}>0.05)$, indicating that the protein level of COX among the groups did not change significantly.

\section{Immunofluorescent staining and western blot analysis for monoacylglycerol lipase}

Monoacylglycerol lipase (MAGL) is an essential enzyme required for the metabolism of glycerol, lipid, and serine. In the NTCA group, the nuclei in the merged image showed a pink fluorescent signal, suggesting the presence of MAGL in the nuclei (Figure 11A,B,C). In the DHCA group (Figure $11 D, E, F$ ) and NC group (Figure 11G,H,I), MAGL located in the cytoplasm showed no overlap with the fluorescent signal from the nuclei. The merged images showed the outlines of the neuron. This result indicated that under the DHCA condition, the mitochondrial membranes were stabilized, and the movement of MAGL from mitochondria in the 
Table 1 List of differentially expressed proteins

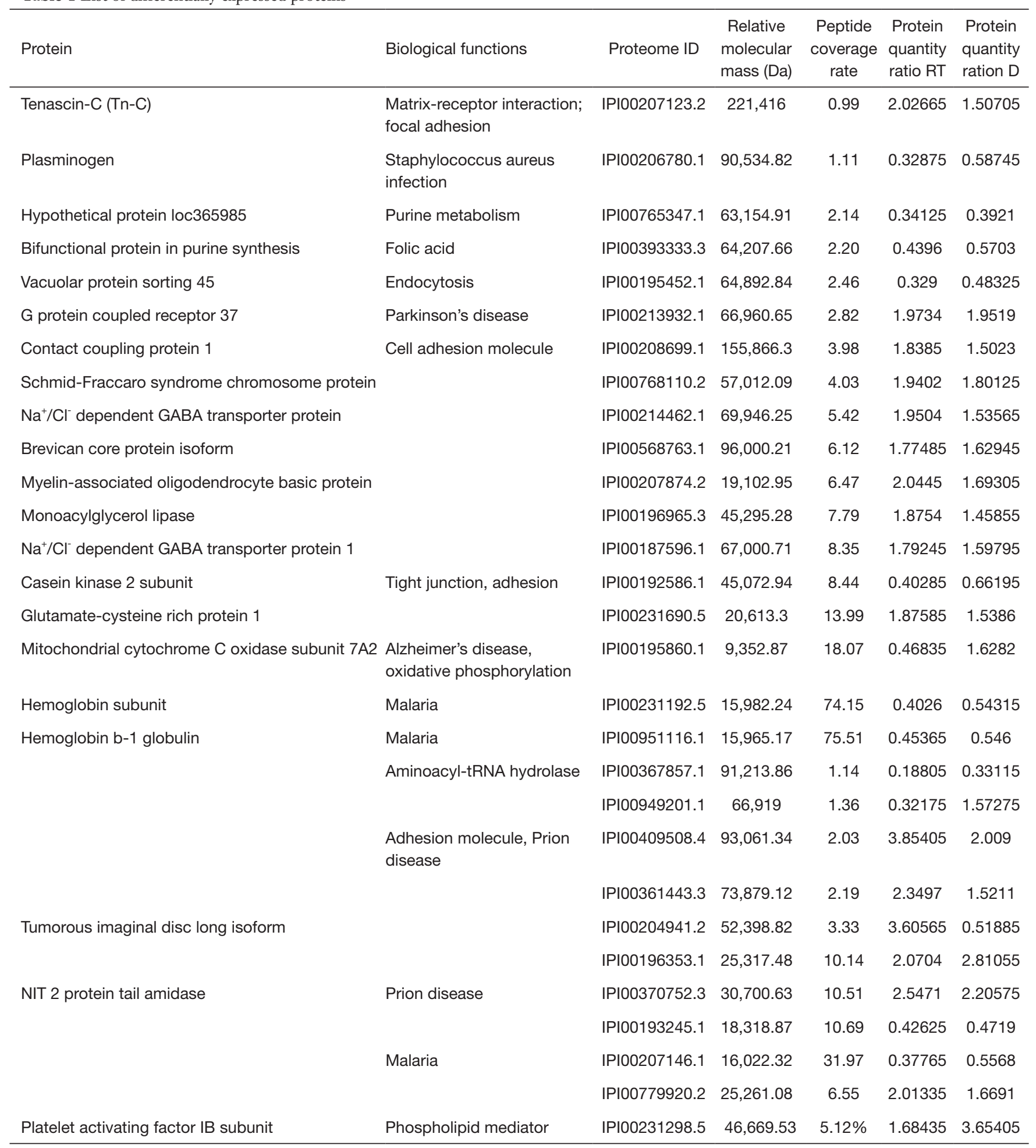



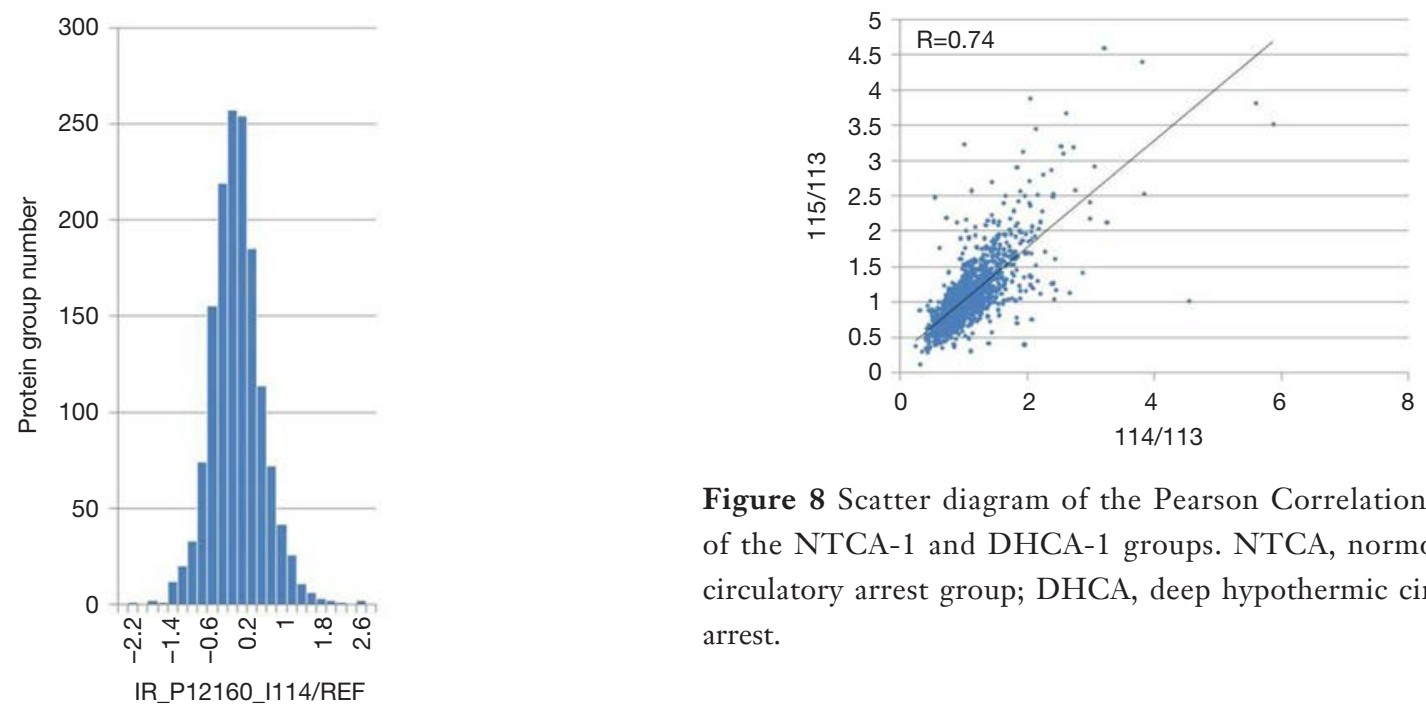

Figure 8 Scatter diagram of the Pearson Correlation analysis of the NTCA-1 and DHCA-1 groups. NTCA, normothermic circulatory arrest group; DHCA, deep hypothermic circulatory arrest.

Figure 7 The quantitative ratio histogram distribution.
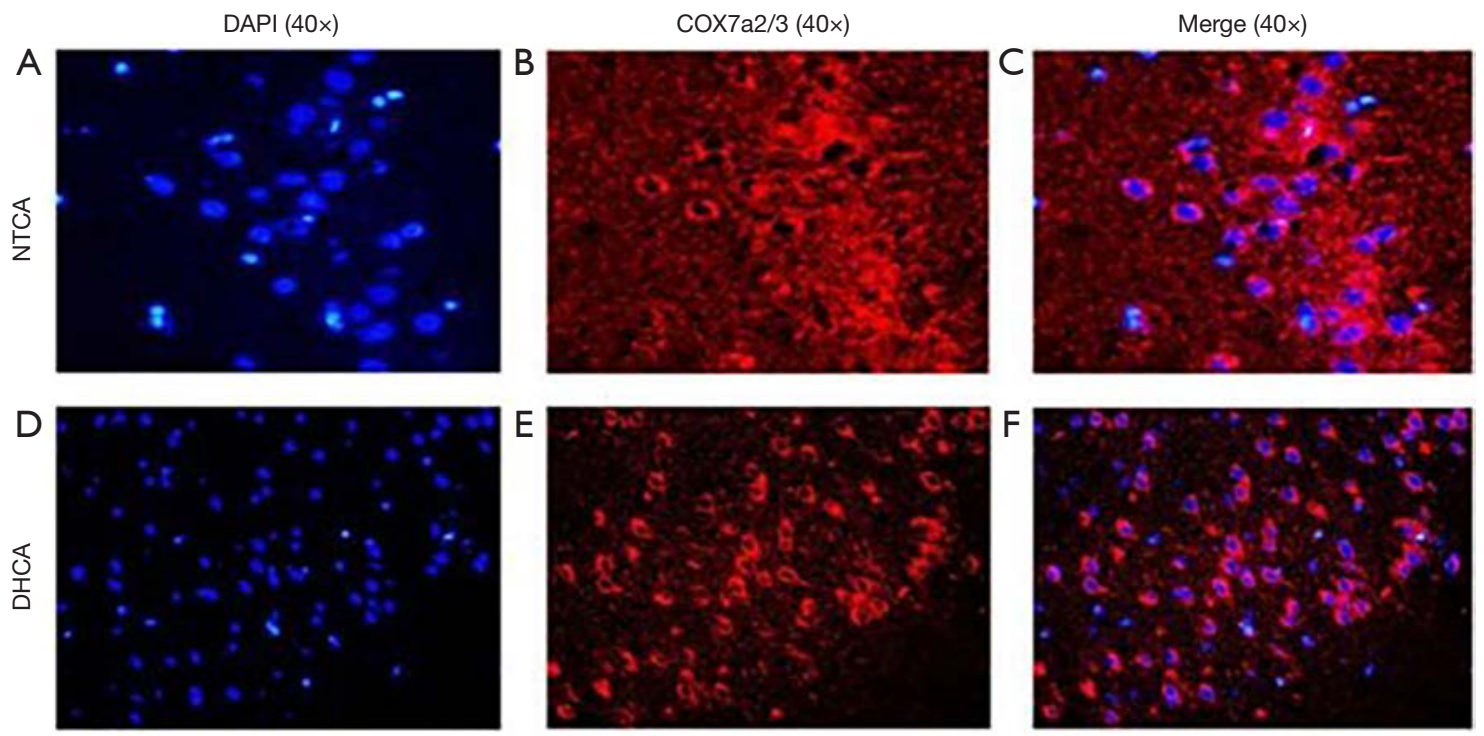

Figure 9 Localization of cytochrome C oxidase in the neurons of NTCA and DHCA groups. (A,B,C) NTCA group performed COX-IV (COX7a2/3) and DAPI immunofluorescence staining. (D,E,F) DHCA group performed COX-IV (COX7a2/3) and DAPI immunofluorescence staining. NTCA, normothermic circulatory arrest group; DHCA, deep hypothermic circulatory arrest; DAPI, 4',6-diamidino-2-phenylindole.

cytoplasm to the nuclei was prevented, which might be one of the mechanisms of neuroprotection.

The western blot result clearly showed that the MAGL protein was around $33 \mathrm{kDa}$, and $\beta$-actin served as the internal control (Figure 12). The grey scale values, ratios to internal control, and average values are shown in Table 3. The grey scale ratios among the groups were not statistically meaningful $(\mathrm{P}>0.05)$, indicating that the protein level of MAGL among the groups did not change significantly.

\section{Discussion}

Comparative proteomics has been widely applied to tumor/ cancer research $(11,12)$, as well as in relation to hypoxia- 


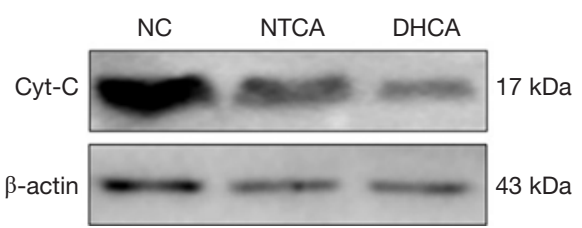

Figure $10 \mathrm{COX}(\mathrm{Cyt}-\mathrm{C})$ protein level in hippocampal samples of NC, NTCA, and DHCA groups. Western blot analysis was performed as described in materials and methods. NC, normal control; NTCA, normothermic circulatory arrest group; DHCA, deep hypothermic circulatory arrest.
Table 2 Relative protein level of COX-IV in NC, NTCA and DHCA groups

\begin{tabular}{lccc}
\hline Grey scale ratio & NC & NTCA & DHCA \\
\hline COX/ $\beta$-actin & 0.88 & 0.62 & 1.01 \\
& 0.17 & 0.14 & 0.94 \\
& 1.69 & 1.10 & 1.16 \\
\hline
\end{tabular}

NTCA, normothermic circulatory arrest; DHCA, deep hypothermic circulatory arrest.
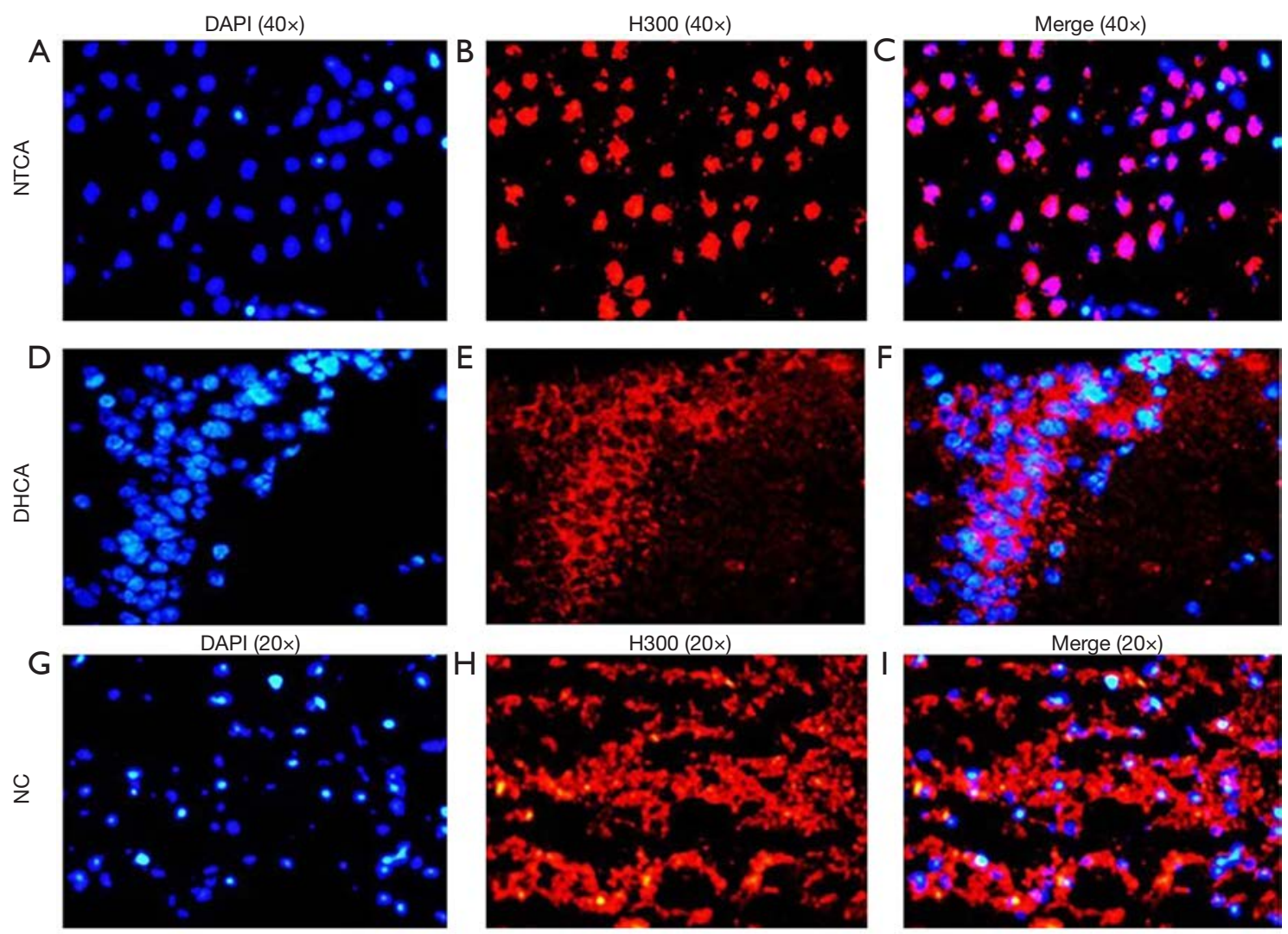

Figure 11 Localization of monoacylglycerol lipase in the neurons of NTCA, DHCA, and NC groups. (A,B,C) NTCA group performed immunofluorescence staining for monoacylglycerol lipase (H300) and DAPI. (D,E,F) DHCA group performed immunofluorescence staining for H300 and DAPI. (G,H,I) DHCA group performed immunofluorescence staining for H300 and DAPI. NC, normal control; NTCA, normothermic circulatory arrest group; DHCA, deep hypothermic circulatory arrest.

ischemia (13). The hippocampus is the area most sensitive to hypoxia-ischemia, and mitochondria are the energy factories of cells; therefore, hippocampal mitochondria are the most sensitive the earliest responsive organelle to hypoxiaischemia. The response of hippocampal mitochondria to hypoxia-ischemia finally determines the apoptosis, necrosis, or damage repair of the hippocampal neurons. The cellular scaffold proteins, enzymes functioning in energy metabolism, and proteins involved in cellular signal transduction might participate in neuroprotection under 


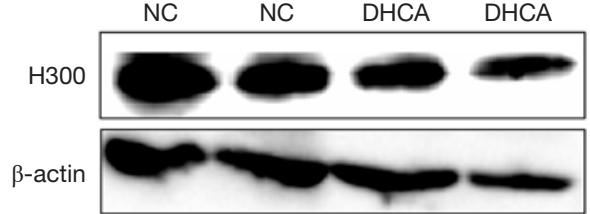

Figure 12 MAGL protein (H300) level in hippocampal samples of NC and DHCA groups. Western blot analysis was performed as described in materials and methods. MAGL, monoacylglycerol lipase; NC, normal control; DHCA, deep hypothermic circulatory arrest.

hypothermic conditions (14).

According to our past research and a previously described method (15), we established a CPB model and then executed circulatory arrest (DHCA). The biggest difference between the last 2 models, besides the similar designed device, perfusion circuit optimization, and microsurgical techniques, was circulatory arrest. The model used for DHCA was similar to many previously described methods $(16,17)$.

Combining iTRAQ (18) and LC-MS/MS (19) technologies, our study finally obtained 1,492 quantitatively meaningful proteins, whose functions were involved in mitochondrial biochemical processes, cell compositions, molecular functioning, and so on. Based on the data of two independent experiments, we obtained 29 statistically meaningful differentially expressed proteins, of which 21 proteins were known and 8 were unknown proteins. Of these differentially expressed proteins, 16 showed upregulation of expression as follows: tenascin-C, G protein-coupled receptor 37 , contact coupling protein 1 , Schmid-Fraccaro syndrome chromosome protein, $\mathrm{Na}^{+} /$ $\mathrm{Cl}$-dependent GABA transporter protein, brevican core protein isoform, myelin-associated oligodendrocyte basic protein, monoacylglycerol lipase, glutamate-cysteine rich protein 1, NIT 2 protein tail amidase, platelet activating factor IB subunit, and 4 other unknown proteins. A total of 10 of the identified differentially expressed proteins showed downregulation of expression: plasminogen, hypothetical protein loc365985, bifunctional protein in purine synthesis, vacuolar protein sorting 45 , casein kinase 2 subunit, hemoglobin subunit, hemoglobin b-1 globulin, and 3 other unknown proteins. Mitochondrial COX subunit 7A2, tumorous imaginal disc long isoform, and an unknown protein showed changes in opposite directions in 2 independent experiments. The differentially
Table 3 Relative protein level of MAGL in NC and DHCA groups

\begin{tabular}{lcc}
\hline Grey scale ratio & NC & DHCA \\
\hline H300/ $\beta$-actin & 1.62 & 1.52 \\
1.07 & 0.41 \\
1.03 & 1.06 \\
& 0.95 & 1.88 \\
\hline
\end{tabular}

MAGL, monoacylglycerol lipase; DHCA, deep hypothermic circulatory arrest.

expressed proteins were involved in many pathological and physiological processes, such as energy metabolism, purine metabolism, material transport across the membrane, lipid metabolism, protein degradation, hydrolase activity, synaptic vesicle circulation, and so on (20,21).

Among the known proteins, many participated in signal transduction and cellular material transport. The vacuolar protein sorting (Vps) proteins are critical for the transport and sorting of membranes and proteins in eukaryotic cells, involved in signal transduction, cytokinesis, gene silencing, and more. There are more than 20 subtypes of $\mathrm{Vps}$ proteins, and they regulate the transmembrane transport by controlling the expression level of their homologous proteins (22). In the DHCA group, the expression level of $\mathrm{Vps}$ protein reduced, so we speculated that under the deep hypothermic condition, energy metabolism level reduced, cell material exchange decreased, and mitochondrial material exchange decreased correspondingly. Phospholipase C can hydrolyze phosphatidylcholine to produce the second messenger diacylglycerol, which then activates protein kinase C. The activated protein kinase $\mathrm{C}$ further transduces the signal to mitogen activated protein kinase (MAPK) to regulate cell proliferation, differentiation, and apoptosis (23). The phospholipase inhibitors can inhibit the release of phosphatidylinositol and phosphatidyl ethanolamine to alleviate ischemic brain damage. In our study, a reduced expression level of inactive phospholipase $\mathrm{C}$ was observed in the DHCA group. Schmid-Fraccaro syndrome chromosome protein is related to $22 \mathrm{q} 11$ development abnormality (24), and its expression level increased during our experiments. The role of phospholipase $\mathrm{C}$ and SchmidFraccaro syndrome chromosome protein in neuroprotection under deep hypothermia requires further investigation. Tid-1 is a chaperon protein of Hsp70 and tumor suppressor 
genes in fly models, and is the key protein in preventing mitochondrial swelling (25).

Of the 29 differentially expressed proteins, this paper focused on the in-depth investigation of 2 proteins. As the terminal enzyme of the mitochondrial respiratory chain, mitochondrial COX subunit is a critical component of the electron transport chain. The COX protein catalyzes its substrate ferrocytochrome $\mathrm{C}$ to transport electrons to oxygen to form $\mathrm{H}_{2} \mathrm{O}$, and also couples to oxidative phosphorylation to produce adenosine triphosphate (ATP) to provide energy for cellular functions and activities. Therefore, COX protein is regarded as the marker enzyme of the mitochondrial respiratory chain (26). Under the hypoxic-ischemic condition, upregulation of COX activity can successfully transport the electrons through the entire respiratory chain, and deliver oxygen at the position of respiratory chain complex IV, and in so doing maintain the ATP biosynthesis. Hence, COX is the critical protein of mitochondrial machinery in determining cell apoptosis, which is also named as "death protein" $(27,28)$. The western blot result showed that the relative protein levels of COX in the DHCA, NTCA, and NC groups did not have a statistically significant difference, meanwhile the immunofluorescent staining result demonstrated that the location of COX protein changed in the DHCA group, indicating that no COX protein biosynthesis or degradation occurred during hyperacute DHCA condition, while it moved from the cytoplasm towards the nuclei. Therefore, maintaining a relatively stable cellular ATP/adenosine diphosphate (ADP) ratio to inhibit neuron apoptosis might be one of the strategies of DHCA neuroprotection.

The enzyme MAGL (H300) is also called lysophospholipase like protein or lysophospholipase homologue. Studies have shown that MAGL links the endocannabinoid and eicosanoid system by hydrolysis of 2 -arachidonic acid to produce arachidonic acid, and thus mediates the inflammatory response in specific tissues. In tumorigenesis, MAGL modulates the balance of the endocannabinoid and eicosanoid network, and controls the inhibitory function of fatty acid to tumor precursor signals, to achieve the effect of anti-tumorigenesis $(29,30)$. The results of western blot showed no significant differences in the relative protein levels of MAGL among the NC, NTCA, and DHCA groups. The immunofluorescent staining results showed that under normal conditions (NC group), MAGL was located in the hippocampal neuron cytoplasm, whereas it was present in the nuclei in the NTCA group, suggesting that severe hypoxic-ischemic damage could stimulate the mislocalization of MAGL from cytoplasmic mitochondria to the nuclei. While under the DHCA conditions, the mitochondrial membrane was stabilized, which inhibited the mislocalization of MAGL, suggesting that alleviation of hypoxic-ischemic brain damage was achieved under the DHCA conditions via inhibiting the release of MAGL from intra- mitochondria to the outside of the organelle.

\section{Conclusions}

Our study found that as an effective neuroprotective strategy, the neuroprotection effect of DHCA is related to 29 identified differentially expressed proteins. Further studies demonstrated that under the DHCA condition, COX protein was released from intra- mitochondria, while the release of MAGL protein from intra-mitochondria to the outside of the organelle was inhibited. Therefore, we speculated that the neuroprotection effect of DHCA is related to the different localization tendency of these two mitochondrial proteins in the cells.

\section{Acknowledgments}

Funding: This work was supported by the Yunnan Natural Science Foundation (2016NS270).

\section{Footnote}

Reporting Checklist: The authors have completed the ARRIVE reporting checklist. Available at http://dx.doi. org/10.21037/atm-21-95

Data Sharing Statement: Available at http://dx.doi. org/10.21037/atm-21-95

Conflicts of Interest: All authors have completed the ICMJE uniform disclosure form (available at http://dx.doi. org/10.21037/atm-21-95). The authors have no conflicts of interest to declare.

Ethical Statement: The authors are accountable for all aspects of the work in ensuring that questions related to the accuracy or integrity of any part of the work are appropriately investigated and resolved. All the methods used in this study were done in accordance with the guidelines of Ethics Committees of Kunming Medical University for use and care of animals. All the experimental protocols were approved by the Ethics Committees of 
Kunming Medical University.

Open Access Statement: This is an Open Access article distributed in accordance with the Creative Commons Attribution-NonCommercial-NoDerivs 4.0 International License (CC BY-NC-ND 4.0), which permits the noncommercial replication and distribution of the article with the strict proviso that no changes or edits are made and the original work is properly cited (including links to both the formal publication through the relevant DOI and the license). See: https://creativecommons.org/licenses/by-nc-nd/4.0/.

\section{References}

1. Kornilov IA, Sinelnikov YS, Soinov IA, et al. Outcomes after aortic arch reconstruction for infants: deep hypothermic circulatory arrest versus moderate hypothermia with selective antegrade cerebral perfusion. Eur J Cardiothorac Surg 2015;48:e45-50.

2. Chau KH, Friedman T, Tranquilli M, et al. Deep hypothermic circulatory arrest effectively preserves neurocognitive function. Ann Thorac Surg 2013;96:1553-9.

3. Markowitz SD, Mendoza-Paredes A, Liu H, et al. Response of brain oxygenation and metabolism to deep hypothermic circulatory arrest in newborn piglets: comparison of $\mathrm{pH}$-stat and alpha-stat strategies. Ann Thorac Surg 2007;84:170-6.

4. Rimmer L, Fok M, Bashir M. The History of Deep Hypothermic Circulatory Arrest in Thoracic Aortic Surgery. Aorta (Stamford) 2014;2:129-34.

5. Herajärvi J, Anttila T, Dimova EY, et al. Exploring effects of remote ischemic preconditioning in a pig model of hypothermic circulatory arrest. Scand Cardiovasc J 2017;51:233-41.

6. Pan XD, Sun LZ, Ma WG, et al. Neuroprotective effect of deep hypothermic circulatory arrest with low priming volume: study in a rabbit model. Thorac Cardiovasc Surg 2008;56:133-9.

7. Sinha K, Das J, Pal P, et al. Oxidative stress: the mitochondria-dependent and mitochondria-independent pathways of apoptosis. Arch Toxicol 2013;87:1157-80.

8. Meade ML, Hoffmann A, Makley MK, et al. Quantitative proteomic analysis of the brainstem following lethal sarin exposure. Brain Res 2015;1611:101-13.

9. Unwin RD, Griffiths JR, Whetton AD. Simultaneous analysis of relative protein expression levels across multiple samples using iTRAQ isobaric tags with 2D nano LC-MS/
MS. Nat Protoc 2010;5:1574-82.

10. Wiśniewski JR, Zougman A, Nagaraj N, et al. Universal sample preparation method for proteome analysis. Nat Methods 2009;6:359-62.

11. Bohnenberger H, Kaderali L, Ströbel P, et al. Comparative proteomics reveals a diagnostic signature for pulmonary head-and-neck cancer metastasis. EMBO Mol Med 2018;10:e8428.

12. Taghipour M, Omidvar A, Razmkhah M, et al. Comparative Proteomic Analysis of Tumor MesenchymalLike Stem Cells Derived from High Grade versus Low Grade Gliomas. Cell J 2017;19:250-8.

13. Wu L, Li H, Li X, et al. Peptidomic Analysis of Cultured Cardiomyocytes Exposed to Acute Ischemic-Hypoxia. Cell Physiol Biochem 2017;41:358-68.

14. Tucker D, Lu Y, Zhang Q. From Mitochondrial Function to Neuroprotection-an Emerging Role for Methylene Blue. Mol Neurobiol 2018;55:5137-53.

15. Madrahimov N, Natanov R, Boyle EC, et al. Cardiopulmonary Bypass in a Mouse Model: A Novel Approach. J Vis Exp 2017;(127):56017.

16. Schubert S, Gerlach F, Stoltenburg-Didinger G, et al. Cerebral expression of neuroglobin and cytoglobin after deep hypothermic circulatory arrest in neonatal piglets. Brain Res 2010;1356:1-10.

17. Gatti G, Benussi B, Currò P, et al. The Risk of Neurological Dysfunctions after Deep Hypothermic Circulatory Arrest with Retrograde Cerebral Perfusion. J Stroke Cerebrovasc Dis 2017;26:3009-19.

18. Szopinska A, Degand H, Hochstenbach J, et al. Rapid response of the yeast plasma membrane proteome to salt stress. Mol Cell Proteomics 2011;10:M111.009589.

19. Wither M, Hansen K, Reisz J. Mass Spectrometry-Based Bottom-Up Proteomics: Sample Preparation, LC-MS/ MS Analysis, and Database Query Strategies. Curr Protoc Protein Sci 2016;86:16.4.1-16.4.20.

20. Sever M, Gunay G, Guler MO, et al. Tenascin-C derived signaling induces neuronal differentiation in a three-dimensional peptide nanofiber gel. Biomater Sci 2018;6:1859-68.

21. Huang $X$, Wang $Y, \operatorname{Nan} X$, et al. The role of the orphan G protein-coupled receptor 37 (GPR37) in multiple myeloma cells. Leuk Res 2014;38:225-35.

22. Shanks SG, Carpp LN, Struthers MS, et al. The Sec1/ Munc18 protein Vps45 regulates cellular levels of its SNARE binding partners Tlg2 and Snc2 in Saccharomyces cerevisiae. PLoS One 2012;7:e49628.

23. Kadamur G, Ross EM. Mammalian phospholipase C. 
Annu Rev Physiol 2013;75:127-54.

24. Chen CP, Ko TM, Chen YY, et al. Prenatal diagnosis and molecular cytogenetic characterization of mosaicism for a small supernumerary marker chromosome derived from chromosome 22 associated with cat eye syndrome. Gene 2013;527:384-8.

25. Linnoila J, Wang Y, Yao Y, et al. A mammalian homolog of Drosophila tumorous imaginal discs, Tid1, mediates agrin signaling at the neuromuscular junction. Neuron 2008;60:625-41.

26. Chen R, Vendrell I, Chen C, et al. Proteomic analysis of rat plasma following transient focal cerebral ischemia.

Biomark Med 2011;5:837-46.

Cite this article as: Gao Y, Han X, Wei L, Yuan Y, Zhao C, Zhang M, Wang Z, Li X, Xu W. Study on the differential proteomics of rat hippocampal mitochondria during deep hypothermic circulatory arrest. Ann Transl Med 2021;9(4):346. doi: $10.21037 /$ atm-21-95
27. Costa RO, Ferreiro E, Oliveira CR, et al. Inhibition of mitochondrial cytochrome c oxidase potentiates $A \beta$ induced ER stress and cell death in cortical neurons. Mol Cell Neurosci 2013;52:1-8.

28. Gennis R, Ferguson-Miller S. Structure of cytochrome c oxidase, energy generator of aerobic life. Science 1995;269:1063-4.

29. Fowler CJ. Monoacylglycerol lipase - a target for drug development? Br J Pharmacol 2012;166:1568-85.

30. Mulvihill MM, Nomura DK. Therapeutic potential of monoacylglycerol lipase inhibitors. Life Sci 2013;92:492-7.

(English Language Editor: J. Jones) 